\title{
Behavioral Cardiology/Cardiac Psychology: Translating research into practice
}

\author{
Robert Allan ${ }^{1}$, Terry M Pace ${ }^{2 *}$ and Yaser Dorri ${ }^{3}$ \\ ${ }^{1}$ Weill Cornell Medical College \& New York-Presbyterian Hospital, USA \\ ${ }^{2}$ University of Oklahoma \& Oklahoma Heart Hospital South, USA \\ ${ }^{3}$ McLaren Family Medicine, USA
}

\begin{abstract}
There is a profound schism between the large epidemiologic database informing behavioral cardiology/cardiac psychology and the modest implementation of psychological services into clinical practice. We completed several online surveys of American Psychological Association Listservs, requesting information about practice in cardiac psychology and found fewer than 15 members with extensive clinical experience in the United States. The unmet need for addressing psychological comorbidities among hospitalized cardiac patients was recently discussed in an editorial in a major cardiology journal. This paper describes two authors' successful practices in cardiac psychology within medical settings. We hope this discussion will foster greater interest in the translation of research into practice among both the cardiology and psychology communities.
\end{abstract}

\section{Introduction}

The scientific field of cardiac psychology, also known as behavioral cardiology and psychocardiology, began in 1959 when Friedman and Rosenman, two cardiologists, invented the "type A behavior pattern (TABP)," the two major symptoms of which are easily aroused anger (free floating hostility) and time pressure (doing too much in too little time) [1,2]. Early research linked type A behavior with increased myocardial infarction (MI; [3]). An often-controversial topic, the TABP has scarcely been studied in recent years; however, a large empirical evidence base has evolved informing cardiac psychology. A PubMed search of the terms "psychosocial factors and cardiovascular disease" now yields more than 52,000 citations. Research links depression, social isolation, anxiety, anger, as well as a number of less researched psychosocial factors, with both the onset and poor treatment outcome of coronary heart disease (CHD). A meta-analysis of 893,500 initially healthy subjects reported that depression is a risk factor for both MI and CHD [4], while another meta-analysis with 317,540 subjects determined that depression is a risk factor for non-fatal and fatal stroke [5]. In 2014, an expert panel convened by the American Heart Association recommended that depression be elevated to risk factor status for patients with acute coronary syndrome (ACS) [6]. Anxiety has been associated with increased risk of cardiovascular mortality, $\mathrm{CHD}$, stroke, and heart failure in a meta-analysis with 2,017,276 subjects [7]. A review of loneliness and social isolation reported that deficiencies in social relationships were associated with an increased risk of CHD and stroke [8]. Anger has been shown to heighten the risk of CHD in healthy individuals and cardiac patients [9], as well as "trigger" MI, stroke, intracranial aneurism rupture, and ventricular arrhythmia [10]. In contrast to these negative emotional states and conditions, optimism has been found to be a robust protective factor against cardiovascular disease [11]. Differing starkly from these studies, which have utilized large numbers of subjects, the most recent Cochrane review [12] contained only 35 clinical trials with 10,703 participants attempting to treat psychosocial risk factors, and thereby reduce cardiac morbidity and mortality, as well as improve quality of life. Psychological interventions led to a reduction in cardiovascular mortality (relative risk $0.79,95 \%$ confidence interval [CI] 0.63 to 0.98), although no effects were observed for total mortality, MI, or revascularization. Psychological interventions improved depressive symptoms (standardized mean difference [SMD] $-0.27,95 \% \mathrm{CI}-0.39$ to -0.15 ), anxiety (SMD $-0.24,95 \% \mathrm{CI}-0.38$ to -0.09 ), and stress (SMD $-0.56,95 \%$ CI -0.88 to -0.24 ), compared with routine care controls. A well done recent randomized trial [13] demonstrated that the addition of stress management enhanced cardiac outcomes during cardiac rehabilitation compared to rehabilitation patients who did not receive such training.

In an attempt to stimulate the field, the American Psychological Association has published four books [14-17], one video [18] and a 10hour professional video series [19] in cardiac psychology. We recently queried APA Listservs from the Divisions of Health Psychology, Behavioral Cardiology, Clinical Psychology, and Counseling Psychology, with fewer than 15 psychologists replying that they were engaged in substantial cardiac psychology practice in the U.S.

\section{What we have done: Examples of cardiac psychology in practice}

In 1981, Robert Allan established the first cardiac support group in the New York Metropolitan area at the Nassau County Chapter of the

${ }^{\star}$ Correspondence to: Terry M Pace, $\mathrm{PhD}$, University of Oklahoma \& Oklahoma Heart Hospital South, 710 Tarkington Dr. Norman, Oklahoma, 73026, USA, E-mail: tpace@ou.edu

Key words: behavioral cardiology, cardiac psychology

Received: December 11, 2018; Accepted: December 21, 2018; Published: December 24, 2018 
American Heart Association. He invited cardiologist Stephen Scheidt, from what was then The New York Hospital - Cornell Medical Center, to attend a group session; Scheidt subsequently invited Allan to study cardiology at Cornell where, in 1983, they established the Coronary Risk Reduction Program. Dr. Scheidt graciously shared his office with Allan for 25 years, until his untimely passing in 2007. During the past 34 years, at what is now Weill Cornell Medical College/New YorkPresbyterian Hospital, in concert with the Nutrition Department and his team, Allan has provided "Preventing Heart Disease" classes to more than 15,000 inpatients and their family members. He has treated many hundreds of cardiac patients with individual psychotherapy and led more than 3,000 cardiac support groups in the Division of Cardiology, cardiac rehabilitation centers, and private practice. Additionally, for the past several years, Allan has provided psychological evaluation and psychotherapy on the step-down coronary care unit (CCU), where he has found fertile ground for collaboration with staff and intervention with patients. This work has been recently described [20]. Of note, it is a small, but nonetheless significant, percentage of the inpatient cardiac population that has an interest in working with a psychologist at Weill Cornell.

Terry M. Pace has worked with an extensive network of professionals at a designated "heart hospital" in Oklahoma. $\mathrm{He}$ conducts daily consultations with patients for psychological distress of any kind. Consultations are generated from elevated scores on the Geriatric Depression Scale, as well as referrals from physicians, nurses, case managers, and chaplain staff, usually $10-12$ a day. Pace is typically able to see about half the referrals, as many patients are in medical procedures, sedated, or discharged.

Pace and Allan make notes into the medical records immediately after seeing each patient, consult with staff before and after, and contact physicians with concerns. They provide assessment, coping techniques, long term recommendations for mental health care, and make referrals for outpatient treatment. Both Allan and Pace make psychopharmacology recommendations to physicians, who ultimately prescribe the medication. Patients often present with multiple diagnoses, including cardiovascular, neurovascular, and peripheral vascular conditions, as well as associated co-morbidities, such as diabetes and chronic obstructive pulmonary disease. Most often, Pace treats acute stress regarding medical issues, hospitalization adjustment issues and complications, depression, suicidal ideation, anxiety and panic, substance abuse (especially methamphetamines and alcohol), posttraumatic stress disorder (mainly from war, as Pace has a large veteran's population). Patients are followed as needed while in the hospital. Some may be seen numerous times for ongoing assessment and psychotherapy.

Pace conducts an outpatient clinic one afternoon a week, following patients who live nearby and are most in need. His service is embedded within a large outpatient cardiology clinic; thus, patients come to one setting for both their cardiac and psychological care. Allan treated patients in the outpatient cardiology department for 25 years; more recently he has moved to a private office, largely because of space limitations in an ever-expanding Cardiology Division. Pace could easily have a full outpatient practice within the medical center, but with the range of his other duties, time does not allow. The majority of physicians readily express appreciation for his services; one cardiologist recently told Pace, "you are the most important doctor here, you help people change their lives, I just fix them up, but you help them to live and care for themselves better." When physicians see the results of psychological services, many are appreciative and eager to collaborate, providing more comprehensive patient care.
Pace delivers two stress management psycho-educational groups each week in the Intensive Cardiac Rehabilitation (ICR) program, following the Medicare approved Pritikin model, which has a holistic framework [21]. The syllabus includes stress physiology and the heart; coping skills, utilizing a model that organizes coping into various modalities, such as relapse prevention, relaxation training, and sleep hygiene. Each patient is billed as part of the bundled ICR program for time in each modality (nutrition, yoga, exercise, psycho-educational stress management groups). There are 10-15 patients in most psychoeducational groups. Pace also provides a weekly open support group for all cardiac patients, using an adaptation of the Ornish model utilized in the Lifestyle Heart Program [22,23]. Usually, 5-10 patients attend the support group.

A systems model of care includes physicians, nurses, chaplains, physical and occupational therapists, dieticians, and family. Educating physicians and nursing staff about psychological aspects of healthcare in a collegial, respectful, and time efficient manner is a major focus. These are often the gatekeepers with the greatest impact on patients' healthcare, and our relationships with them are paramount to being effective. We also occasionally provide stress management or related enrichment workshops for staff development.

A notable aspect of our practice is that we are both on call 24 hours a day. Pace has on-call psychologists to cover weekends and holidays. We also offer training to medical and psychology students.

Pace believes his practice has been successful for four primary reasons. First, he obtained full support from administrative and physician leaders in order to establish his position and advocate for the value of psychological services. Second, using a psychological screening tool has created a natural flow of patients and increased awareness of psychological needs among other providers. Third, embedding his role into the same work patterns and locations as physicians and other providers makes him visible, accessible, and demystifies psychological services. Fourth, when patients show improvement from psychological interventions, it is easy to build trust and confidence with other health care providers.

\section{Discussion}

Every psychological intervention clinical trial has utilized group psychotherapy as the treatment modality, with an ultimate goal of reducing cardiac events, which cardiologist Scheidt once referred to as "the holy grail of behavioral cardiology." However, psychologists have long provided individual psychotherapy for depression, anxiety, deficiencies in social relationships, and anger - all risk factors with robust empirical relationships to $\mathrm{CHD}$. Patients with cardiac diagnoses other than CHD can also benefit from psychological intervention, such as cardiac arrest survivors, patients with implantable cardioverter defibrillators (ICDs), pacemakers, and external life vests; congestive heart failure, valvular repair or replacement; cardiomyopathy, Takasubo cardiomyopathy (stress cardiomyopathy; "Broken Heart Syndrome"); and those needing various behavioral-lifestyle modifications (e.g., smoking cessation, substance abuse, pain management, insomnia, medical adherence). Additionally, many cardiac patients have other co-morbid medical conditions that can impact heart health or overall quality of life and may be appropriate targets of psychological intervention for lifestyle change, such as diabetes, kidney disease, sleep apnea, chronic pain, and cognitive impairment. Finally, cardiac patients may exhibit increased baseline rates of many common psychological stressors and disorders such as work and family stress, depression, anxiety, post-traumatic stress, other severe mental illnesses and substance abuse disorders $[14,15]$. 
Quite importantly, we believe that psychologists should gain considerable experience before attempting clinical trials. Practice as a cardiac psychologist comes with a steep learning curve as it is necessary to have a thorough grounding in cardiology in order to garner respect from physicians and medical staff as well as patients. "A Whirlwind Tour of Cardiology for the Mental Health Professional" is a resource that has been provided for this purpose [24].

\section{Should every cardiology division utilize a cardiac psychologist?}

Why not? There is such an abundance of data linking psychosocial factors to CHD, what reasons could there be to object? Moreover, patients with other cardiac diagnoses can also benefit from the emotional support of a psychologist. With the intense pressures on cardiologists in the current practice environment, there is little time available to address the emotional aspects of heart disease, which can be truly challenging for some patients. The American Psychologist recently published a special issue addressing in more depth the research base for the practice of cardiac psychology that we have reviewed here [25]. The lead authors in this issue emphasized the point that most of the major etiological factors contributing to cardiovascular disease have a psychological component which is potentially modifiable and that the expertise of psychologists offer a skill set to complement and help to coordinate the interventional work of cardiologists and other healthcare providers.

A substantial segment of the cardiac population is on Medicare and reimbursement is available for psychological evaluation as well as individual and group psychotherapy. Commercial insurance companies also routinely reimburse for these services. Essentially, a cardiac psychologist can be self-sufficient, costing the Cardiology Division little to no funding.

Practice as a cardiac psychologist is a rewarding endeavor. In sum, we need a surge in both clinical practice and clinical trials in order to bring this field to fruition and overcome the astonishing schism between research and practice.

\section{References}

1. Ludmir J, Bui MP, Small JA (2018) The challenge of Identifying and Addressing Psychological Comorbidities. J Am Coll Cardiol 71: 1590-1593.

2. Friedman M, Rosenman RH (1959) Association of specific overt behavior pattern with blood and cardiovascular findings; blood cholesterol level, blood clotting time, incident of arcus senilis, and clinical coronary artery disease. J Am Med Assoc 169: 1286-1296. [Crossref]

3. Rosenman RH, Brand RJ, Jenkins CD, Friedman M, Straus R, et al. (1975) Coronary heart disease in the Western Collaborative Group Study: Final follow-up experience of 8 1/2 years. JAMA 233: 872-877. [Crossref]

4. Gan Y, Gong Y, Tong X, Sun H, Cong Y, et al. (2014) Depression and the risk of coronary heart disease: a meta-analysis of prospective cohort studies. BMC Psychiatry 14: 371. [Crossref]

5. Pan A, Sun Q, Okereke OI, Rexrode KM, Hu FB (2011) Depression and risk of stroke morbidity and mortality: a meta-analysis and systematic review. JAMA 306: 12411249. [Crossref]

6. Lichtman JH, Froelicher ES, Blumenthal JA, Carney RM, Doering LV, et al. (2014) Depression as a risk factor for poor prognosis among patients with acute coronary syndrome: systematic review and recommendations a scientific statement from the American Heart Association. Circulation 129: 1350-1369 [Crossref]

7. Emdin CA, Odutayo A, Wong CX, Tran J, Hsiao AJ, et al. (2016) Meta-analysis of anxiety as a risk factor for cardiovascular disease. Am J Cardiol 118: 511-519. [Crossref]

8. Valtorta NK, Kanaan M, Gilbody S, Ronzi S, Hanratty B (2016) Loneliness and social isolation as risk factors for coronary heart disease and stroke: systematic review and meta-analysis of longitudinal observational studies. Heart 102: 1009-1016. [Crossref]
9. Chida Y, Steptoe A (2009) The association of anger and hostility with future coronary heart disease: a meta-analytic review of prospective evidence. $J$ Am Coll Cardiol 53: 936-946. [Crossref]

10. Mostofsky E, Penner EA, Mittleman MA (2014) Outbursts of anger as a trigger of acute cardiovascular events: a systematic review and meta-analysis. Eur Heart $J 35$ : 1404-1410. [Crossref]

11. Boehm JK, Kubzansky LD (2012) The heart's content: the association between positive psychological well-being and cardiovascular health. Psychol Bull 138: 655-691. [Crossref]

12. Richards SH, Anderson L, Jenkinson CE, Whalley B, Rees K, et al. (2017) Psychological interventions for coronary heart disease. Cochrane Database Syst Rev 4: CD002902. [Crossref]

13. Blumenthal JA, Sherwood A, Smith PJ, Watkins L, Mabe S, et al. (2016). Enhancing cardiac rehabilitation with stress management training: a randomized clinical efficacy trial. Circulation 133: 1341-1350. [Crossref]

14. Allan R, Scheidt S (1996) Heart \& Mind: The Practice of Cardiac Psychology, Washington, DC USA.

15. Allan R, Fisher J (2012) Heart \& Mind: The Practice of Cardiac Psychology (second edition), Washington, DC, USA.

16. Dornelas E (2008) Psychotherapy with Cardiac Patients. Washington, DC, USA.

17. Burg MM (2017) Psychological treatment of cardiac patients. American Psychological Association, Washington DC, USA.

18. Allan R (2003) Cardiac Psychology. American Psychological Association Psychotherapy Training Video Series, Washington DC, USA.

19. Allan R (2014) Heart and Mind: Contemporary Issues in Cardiac Psychology, a video on demand continuing education series. Washington, DC, USA.

20. Allan R (2018) A psychologist on the stepdown coronary care unit. J Integr Cardiol 4: $1-3$.

21. Pitikin, Intensive Cardiac Rehabilitation Program.

22. Ornish D, Brown SE, Scherwitz LW, Billings JH, Armstrong WT, et al. (1990) Can lifestyle changes reverse coronary heart disease? The Lifestyle Heart Trial. Lancet 336: 129-133. [Crossref]

23. Vizza J (2012) Comprehensive Lifestyle Intervention and Group Support, Heart and Mind: the Practice of Cardiac Psychology, second edition, 401-416.

24. Fisher J (2012) A whirlwind tour of cardiology for the mental health practioner. Heart $\&$ Mind: The Practice of Cardiac Psychology (second edition), Washington, DC, USA.

25. Stoney CM, Kaufmann PG, Czaiowaski SM (2018) Cardiovascular disease: Psychological, social and behavioral influences. Am Psychol 73: 949-954. [Crossref]

Copyright: (C2018 Allan R. This is an open-access article distributed under the terms of the Creative Commons Attribution License, which permits unrestricted use, distribution, and reproduction in any medium, provided the original author and source are credited. 